\author{
모사 디젤 화학반응 메커니즘의 각 성분이 \\ 화학적 점화 지연 시간에 미치는 영향에 관한 기초 연구 \\ 김 규 진 ${ }^{1)} \cdot$ 이 상 열 ${ }^{2} \cdot$ 민 경 덕 ${ }^{* 1}$ \\ 서울대학교 기계항공공학부 ${ }^{1)} \cdot$ 서울대학교 협동과정 자동차공학과 ${ }^{2}$
}

\title{
Fundamental Study on the Chemical Ignition Delay Time of Diesel Sumogate Components
}

\author{
Gyujin $\mathrm{Kim}^{1)} \cdot$ Sangyul Lee ${ }^{2)} \cdot$ Kyoungdoug $\mathrm{Min}^{* 1)}$ \\ ${ }^{1)}$ Department of Mechanical and Aerospace, Seoul National University, Seoul 151-744, Korea \\ ${ }^{2)}$ Interdisciplinary Program in Automotive Engineering, Seoul National University, Seoul 151-744, Korea \\ (Received 21 June 2012 / Revised 22 August 2012 / Accepted 28 August 2012)
}

\begin{abstract}
Due to its accuracy and efficiency, reduced kinetic mechanism of diesel surrogate is widely used as fuel model when applying 3-D diesel engine simulation. But for the well-developed prediction of diesel surrogate reduced kinetic mechanism, it is important to know some meaningful factors which affect to ignition delay time. Meanwhile, ignition delay time consists of two parts. One is the chemical ignition delay time related with the chemical reaction, and the other is the physical ignition delay time which is affected by physical behavior of the fuel droplet. Especially for chemical ignition delay time, chemical properties of each fuel were studied for a long time, but researches on their mixtures have not been done widely. So it is necessary to understand the chemical characteristics of their mixtures for more precise and detailed modeling of surrogate diesel oil. And it shows same ignition trend of paraffin mixture with those of single component, and shorter ignition delay at low/high initial temperature when mixing paraffin and toluene.
\end{abstract}

Key words : Surrogate diesel model(모사 디젤 모델), Chemical ignition delay time(화학적 점화 지연 시간), n-Dodecane(노멀 도데케인), Reduced chemical mechanism(축소 화학 반응식), $\mathrm{CFD}$ (전산 유체 역학)

\section{Nomenclature}

NTC : negative temperature coefficient

EGR : exhaust gas recirculation

PM : particulate matter

CAD : crank angle degree [deg]

CFD : computational fluid dynamics

SOI : start of injection [deg]

SOC : start of combustion [deg]

\footnotetext{
"Corresponding author, E-mail: kdmin@snu.ac.kr
}

\section{1. 서 론}

엔진 내부의 유동 및 연소 현상에 대한 해석에서 전산 유체역학(CFD)은 엔진 실험에 비해 몇 가지 이 점을 지니고 있다. 왜냐하면 온도, 압력, 당량비 및 실린더의 형상 등 여러 변수에 대한 제어에 있어 시·공간적 제약이 없을 뿐 아니라, 실린더 내부의 유동 분포 및 각 화학종들의 생성 및 소멸 등을 가시 화하고 정량적으로 살펴볼 수 있기 때문이다. 이런 이유로 전산 유체 역학은 엔진 연구에 오랫동안 사 용되어 왔으며, 모델의 정확도와 컴퓨터의 계산 능 력의 향상으로 엔진 연구에 있어 실험적 연구 못지 
않게 중요한 분야로 자리 잡고 있다.

디젤 엔진 해석 분야에서도 연료의 화학반응 메 커니즘, 분무 및 분열 모델, 연소 모델, 배기 배출물 모델 등 디젤 엔진 내에서의 연소 과정 전반에 대하 여 많은 연구가 진행되고 있다. 하지만 이러한 해석 적 모델을 이용한 엔진 연소 해석이 신뢰도를 얻기 위해서는 각 세부 모델들의 정확도뿐만 아니라 수 치해석적인 부분 또한 검증이 되어야만 한다.

특히 연료의 화학반응 모델의 경우, 모델의 신뢰 도를 얻기가 매우 어렵다. 이는 실제 사용되는 디젤 연료에는 수 백 종의 화학종들이 복잡한 비율로 섞 여 있어 정확히 모사하기가 현실적으로 불가능할 뿐만 아니라 ${ }^{1)}$, 각 화학종들의 화학 반응을 일일이 반영하기에는 계산 시간이 너무 오래 걸리기 때문 이다. 이러한 이유로, 현재 디젤 엔진 해석을 위한 연료로 단일 화학종인 노멀 헵탄(N-heptane, $\left.C_{7} H_{16}\right)$ 의 축소화학 메커니즘이 주로 사용되고 있다. ${ }^{2-4)}$ 이 는 노멀 헵탄이 단일 화학종 중에서 점화 지연 특성 이 실제 디젤유와 가장 흡사하기 때문이다. ${ }^{1)}$

하지만 노멀 헵탄을 이용한 모델은 몇 가지 문제 점이 존재한다. 먼저 디젤유의 물리적 특성을 잘 모 사하지 못한다. 노멀 헵탄은 분자량이 100 이지만, 실제 디젤유는 종류에 따라 약 분자량 180 200 사이 의 물질이기 때문에, 연료 액적의 물리적 거동에 영 향을 미칠 수 있다. 두 번째는 배기 배출물 특성을 잘 모사하지 못한다. 디젤 엔진에서 주로 배출되는 배기가스 중에서 PM의 생성은 디젤유 내의 방향족 성분의 특성 및 거동에 영향을 받기 때문에 방향족 성분이 없는 노멀 헵탄은 이를 모사하지 못하는 한 계가 있다.

따라서 디젤 엔진 해석에서는 단일 화학종인 노 멀 헵탄보다 실제 디젤유의 화학적, 물리적 거동을 잘 모사할 수 있는 모사 디젤(Diesel Surrogate)을 적 용할 필요성이 있다.

시중에 판매되는 디젤유는 대표적으로 파라핀 (paraffins), 사이클로 파라핀(Cyclo-paraffins), 방향 족 물질(aromatics)로 구성되어 있으며, 탄소 수 또한 7 18으로 매우 다양하다. 즉, 상용 디젤유는 서로 다 른 화학식을 가지는 수백 종의 화학종의 혼합물이 다. 이는 모사 디젤유를 이용한 모델이 한계가 있음
을 의미한다. 왜냐하면 디젤유를 구성하는 각 물질 의 화학반응식 및 화학반응에 참여하는 중간 생성 물질들을 반응 모델에 모두 고려한다는 것은 계산 시간과 효율이 매우 떨어지기 때문이다. 따라서 모 사 디젤 모델의 개발을 위해서는 다양한 방법을 이 용한 축소 화학 반응식을 이용한다.

디젤유의 모사 화학반응 메커니즘에 관한 연구는 활발하게 진행되어 왔다. P. Zhukov 등은 노멀 데케 인(N-decane, $\left.C_{10} H_{22}\right)$ 에 대한 화학반응 모델 개발 및 실험적 연구를 통하여 노멀 파라핀의 자발화 특성 에 대한 연구를 수행하였으며 ${ }^{5)}$, K. Narayanasmway 등은 방향족 물질의 산화 과정에 대한 실험적 연구 를 수행하였다. ${ }^{6}$ 또한 M. Hartmann등은 이소 옥탄 (Iso-octane, $C_{8} H_{18}$ )과 톨루엔(Toluene, $C_{7} H_{8}$ )의 혼합 물의 연소에 대한 실험적 연구를 수행하였다. ${ }^{7)}$ 하지 만 위의 기존 연구들은 혼합물 자체에 대한 실험적 연구가 대부분이어서, 혼합물의 각 구성성분이 전 체 혼합물에 미치는 영향을 알기 어렵다.

본 연구실에서는 이미 CAI 연소 해석을 위한 가 솔린의 모사 화학반응 메커니즘을 개발한 바 있으 며, ${ }^{8,9)}$ 고분자인 디젤유의 특성을 모사하기 위해서 노멀 도데케인(N-dodecane, $C_{12} H_{26}$ )에 대한 축소화 학 반응 메커니즘을 개발한 바 있다. 위 연구를 토대 로 가솔린 메커니즘의 톨루엔의 화학 반응 모델을 방향족(Aromatics)의 대표적인 물질로 선정하고, 가 솔린 메커니즘의 이소 옥탄과 노멀 도데케인을 파 라핀(paraffins)의 대표적인 물질로 선정한 모사 디 젤 모델을 개발하였다. ${ }^{10)}$ 개발된 메커니즘의 계산 시간은 기존 메커니즘에 비해 단일 화학종의 경우 약 10 배 이상 차이가 발생하며, 구성요소가 추가되 어 반응이 커질 경우 기하학적으로 커지 게 된다.

한편, 디젤 엔진에서의 연소는 연료의 분사 직후 바로 진행되지 않고 일정한 지연 시간을 지난 후 발 생하게 된다. 이를 점화 지연 시간(Ignition delay time)이라고 하는데, 연소의 시작 시점(SOC)과 연료 의 분사시점(SOI)의 차이로 정의되며 점화 지연의 원인에 따라 물리적 점화지연 시간과 화학적 점화 지연 시간으로 나뉜다. 물리적 점화 지연은 연료가 분사된 후 연소반응이 일어날 수 있는 증기 상태로 분열, 미립화 되는데 걸리는 시간을 의미하며, 화학 
적 점화 지연은 증기 상태의 연료가 공기와 반응을 시작하여 자발화가 일어날 수 있을 때까지 걸리는 시간을 의미한다. ${ }^{11}$

따라서 본 연구에서는, 개발된 모사 디젤 모델의 각 성분의 상대적 비율을 변화시켜 가면서 전체 혼 합물의 화학적인 점화 지연 시간의 영향을 알아보 는 것을 목표로 하였다.

\section{2. 해석 조건 및 표본 선정}

모사 디젤유를 이루는 대표적인 세 성분인 노멀 도데케인, 이소 옥탄, 톨루엔을 $100 \%$ 로 하는 기준 해석 표본을 만들고 이들의 비율을 조금씩 조합해 보면서 점화 지연 시간을 비교해보았다. 이를 통하 여, 모사 디젤유를 구성하는 각 화학종들의 물리적 점화 지연 시간이 전체 모사 디젤유의 점화 지연에 어떠한 영향을 미치는지 알아보도록 한다.

계산은 화학 반응 분석 소프트웨어인 CHEMKIN PRO 4.1을 사용하여 수행되었으며, ${ }^{12)}$ 계산에 사용 된 세부 조건은 Table 1과 같다. 또한 점화 지연 시간 은 생성 물질의 최대 온도가 $1400 \mathrm{~K}$ 를 처음 넘어서 는 시간을 기준으로 하였다.

Table 1 Simulation conditions

\begin{tabular}{|c|c|}
\hline Description & Specification \\
\hline Fuel type & $\begin{array}{c}\text { Iso-octane (31 species \& 45 reactions) } \\
\text { N-dodecane (32 species \& 43 reactions) } \\
\text { Toluene (25 species \& 33 reactions) }\end{array}$ \\
\hline Ambient temperature & $700 \sim 1200 \mathrm{~K}$ \\
\hline Fuel temperature & $373 \mathrm{~K}$ \\
\hline Ambient pressure & 40 bar \\
\hline Oxygen contents & $21 \%$ (volume fraction) \\
\hline Combustion condition & Stoichiometric condition \\
\hline
\end{tabular}

\section{3. 해석 결과 및 분석}

해석 결과는 기본적으로 분위기 압력 및 산소 농 도 등의 변수는 고정시킨 상태에서 초기온도 $\mathrm{T}$ 의 역수와 점화 지연 시간의 관계를 그래프로 나타내 었다.

\section{1 단일 성분}

Fig. 1 과 2는 각 화학종을 정적 조건에서의 실험

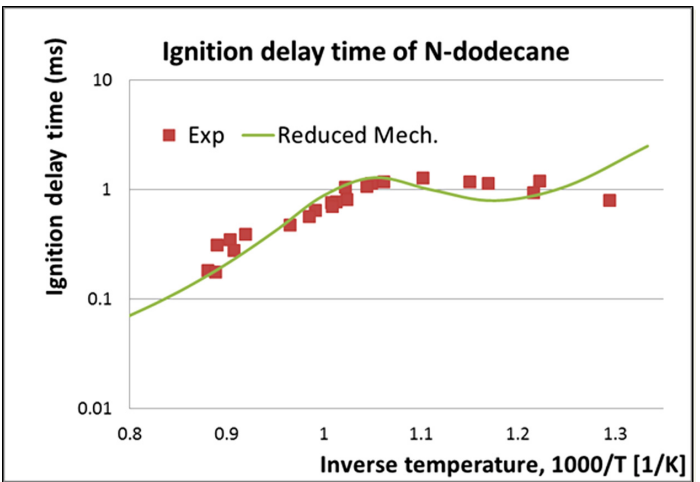

Fig. 1 Ignition delay time of $\mathrm{N}$-dodecane at $\mathrm{p}=20$ bar, elevated temperature under stoichiometric condition

결과와 개발된 축소 화학 반응 메커니즘을 이용하 여 같은 조건에서 계산된 결과를 비교한 그래프이 다. 그래프는 온도의 역수와 $\mathrm{ms}$ 단위의 점화 지연 시 간으로 표현하였다.

Fig. 1은 노멀 도데케인을 정적 조건에서 압력 20 bar, 공연비 1 , 화학종과 공기가 충분히 혼합된 조건 에서 실험한 결과 ${ }^{13)}$ 와 S. Lee 등에 의해 개발된 축소 화학 반응 메커니즘 ${ }^{10)}$ 을 이용하여 계산된 점화 지연 결과를 비교하였다.

Fig. 2는 이소 옥탄과 톨루엔을 정적 조건에서 압 력 $40 \mathrm{bar}$, 공연비 1, 화학종과 공기가 충분히 혼합된 조건에서의 실험한 결과와 본 연구실에서 기존에 개발된 축소 화학 반응 메커니즘을 이용하였다. ${ }^{89}$

Fig. 1 과 2를 통하여, 개발된 각 성분의 축소 화학 반응 메커니즘은 동일 조건의 실험 결과와 잘 일치 함을 확인하였다.

한편 모사 디젤유의 성분으로 선택한 이소옥탄과 노멀 도데케인, 그리고 톨루엔 각각을 단일 연료로써 분사하였을 경우의 화학적인 점화 지연 시간에 관한 결과는 Fig. 3 과 같다. 그래프의 $\mathrm{x}$ 축은 온도의 역수, $\mathrm{y}$ 축은 $\mathrm{ms}$ 단위의 점화 지연 시간으로 나타내었다.

먼저 세 종류의 화학종에서 공통적으로 초기온도 가 증가할수록 점화 지연 시간이 짧아지는 경향을 보인다. 이는 반응물의 온도가 높아질수록 화학반 응이 더욱 활발해지기 때문이다.

화학종에 따른 점화 지연 시간은 크게 두 가지 차 이점을 보인다. 첫 번째로 톨루엔은 노멀 도데케인 이나 이소 옥탄에 비해 점화 지연 시간이 길게 나타 

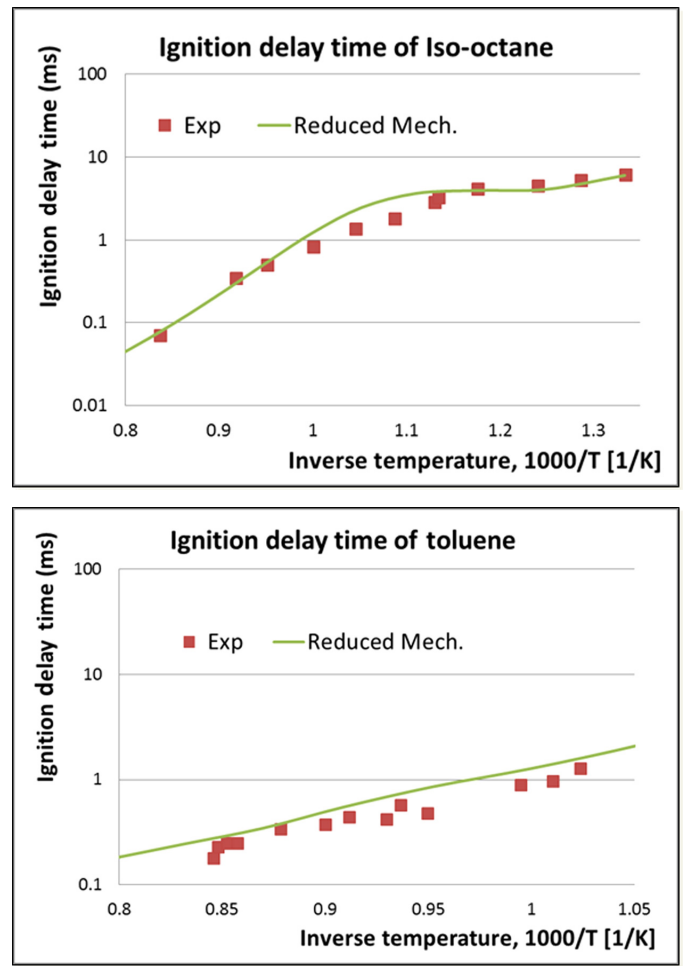

Fig. 2 Ignition delay time of Iso-octane and Toluene at $\mathrm{p}=40$ bar, elevated temperature under stoichiometric condition

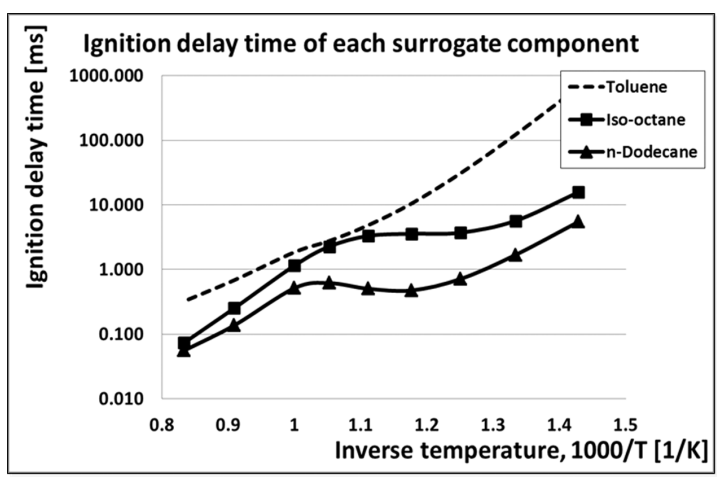

Fig. 3 Ignition delay time of each surrogate component at $\mathrm{p}=40$ bar, elevated temperature under stoichiometric condition

나며, 두 번째로 톨루엔은 나머지 두 화학종에서 발 견되는 NTC 영역이 나타나지 않는다. 상대적으로 긴 점화 지연 시간은 고리형 구조로 인한 낮은 반응 성에 기인한다. 또한 NTC 영역이 나타나지 않는 것 은 Fig. 4와 같이 초기 온도 영역에 따라 두 가지 반

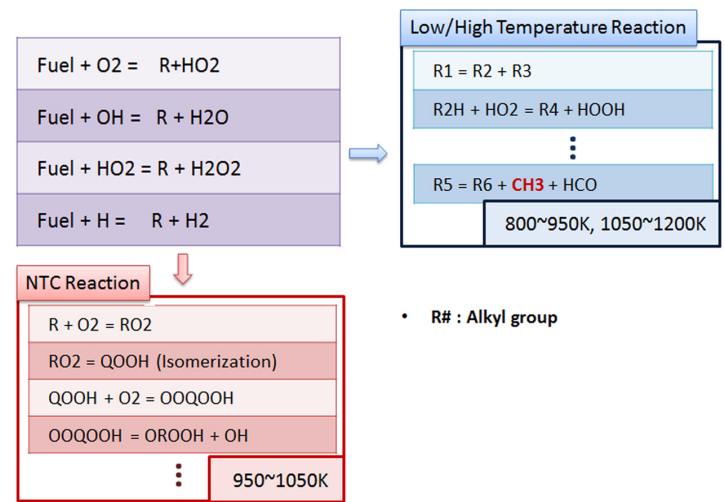

Fig. 4 Reaction path of paraffin group

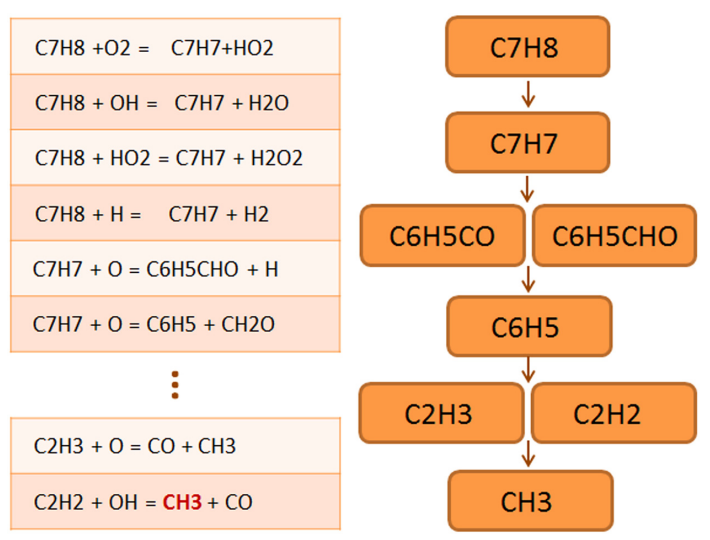

Fig. 5 Reaction path of Toluene

응 경로를 같은 파라핀 족과는 달리, Fig. 5 처럼 톨루 엔은 단일 경로로 반응이 진행되기 때문이다.

\subsection{2성분 혼합물}

\subsection{1 노멀 도데케인과 이소 옥탄의 혼합물}

먼저 노멀 도데케인, 이소 옥탄을 Table 2 와 같은 비율로 혼합한 혼합물 ${ }^{8-10)}$ 의 점화 지연 시간은 Fig. 6 과 같다. 그래프는 마찬가지로 온도의 역수와 $\mathrm{ms}$ 단 위의 점화 지연 시간으로 나타내었다. 맨 아래의 긴 점선 그래프가 노멀 도데케인, 맨 위의 짧은 점선 그 래프가 이소 옥탄의 점화 지연 시간이다.

이소 옥탄의 상대적인 혼합 비율이 증가할수록 점화 지연 시간이 증가하였다. 즉, 노멀 도데케인과 이소 옥탄의 혼합물은 각각의 단일 성분의 점화 지 연 결과의 경향성에 벗어나지 않았다. 이는 노멀 도 데케인과 이소 옥탄은 같은 파라핀 계열의 화학종 
Table 2 Case conditions for $n$-dodecane $\&$ iso-octane mixture (composition was calculated as mole(volume) percent)

\begin{tabular}{|c|c|c|}
\hline Case number & n-dodecane (\%) & iso-octane (\%) \\
\hline 1 & 90 & 10 \\
\hline 2 & 70 & 30 \\
\hline 3 & 50 & 50 \\
\hline 4 & 30 & 70 \\
\hline 5 & 10 & 90 \\
\hline
\end{tabular}

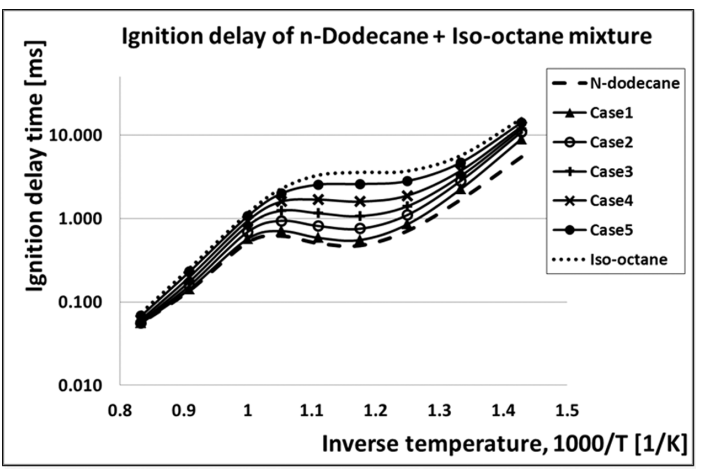

Fig. 6 Ignition delay time of mixtures of n-dodecane and iso-octane mixtures at $\mathrm{p}=40 \mathrm{bar}$, elevated temperature under stoichiometric condition

으로, 비슷한 반응 경로를 통하여 반응이 진행되기 때문이다. 한편 높은 초기온도에서는 반응이 활발 하므로, 이소 옥탄의 포함 비율에 큰 영향 없이 점화 지연 시간이 비슷하다. 또한 낮은 초기온도에서는 반응성이 낮기 때문에 이소 옥탄을 약간만 첨가하 여도 점화 지연 시간이 길어진다.

\subsection{2 파라핀 족과 톨루엔의 혼합물}

노멀 도데케인과 이소 옥탄은 동일한 파라핀 계 열의 화학종으로 비슷한 반응 경로를 따르므로, 두 연료는 파라핀 족으로 묶어 Table 3 과 같은 비율로 혼합 ${ }^{8-10)}$ 하였다.

선정된 표본을 토대로 각 초기온도에서 압력 40 $\mathrm{bar}$,공연비 1 의 조건으로 계산된 파라핀과 톨루엔 혼합물의 점화 지연 시간은 Fig. 7 과 같다. 그래프는 마찬가지로 온도의 역수와 $\mathrm{ms}$ 단위의 점화 지연 시 간으로 나타내었다. 두 그래프 모두 긴 점선이 파라 핀(노멀 도데케인 또는 이소 옥탄)의 점화 지연 그 래프이고, 맨 위의 짧은 점선이 톨루엔의 점화 지연 그래프이다.

두 그래프 모두 크게 2 가지의 경향을 보인다. 첫
Table 3 Case conditions for paraffin \& toluene mixture (composition was calculated as mole(volume) percent)

\begin{tabular}{|c|c|c|}
\hline Case number & Paraffin (\%) & Toluene (\%) \\
\hline 1 & 90 & 10 \\
\hline 2 & 70 & 30 \\
\hline 3 & 50 & 50 \\
\hline 4 & 30 & 70 \\
\hline 5 & 10 & 90 \\
\hline
\end{tabular}
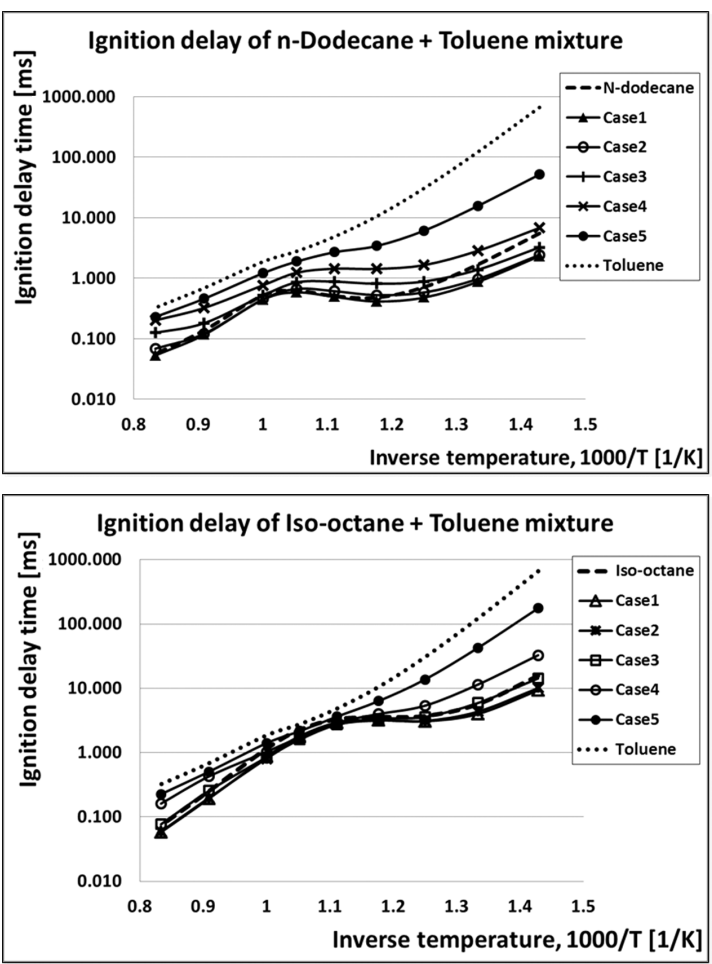

Fig. 7 Ignition delay time of mixtures of paraffins and toluene mixtures at $\mathrm{p}=40$ bar, elevated temperature under stoichiometric condition

번째로, 톨루엔의 상대적인 비율이 증가할수록 혼 합물의 NTC 영역은 점점 줄어든다. 이는 반응성이 낮고 NTC 영역이 존재하지 않는 톨루엔의 상대적 인 양이 늘어나면서, 온도 영역에 따라 두 가지 반응 경로를 갖던 파라핀 족이 톨루엔 첨가로 인해 반응 경로가 단일화되기 때문이다. Fig. 8에서도 볼 수 있 듯이, 톨루엔의 첨가로 인하여 초기온도가 저온이 거나 고온일 때의 반응에 영향을 미치면서 NTC 반 응이 줄어든다.

두 번째는 초기 온도가 고온인 영역과 저온인 영 


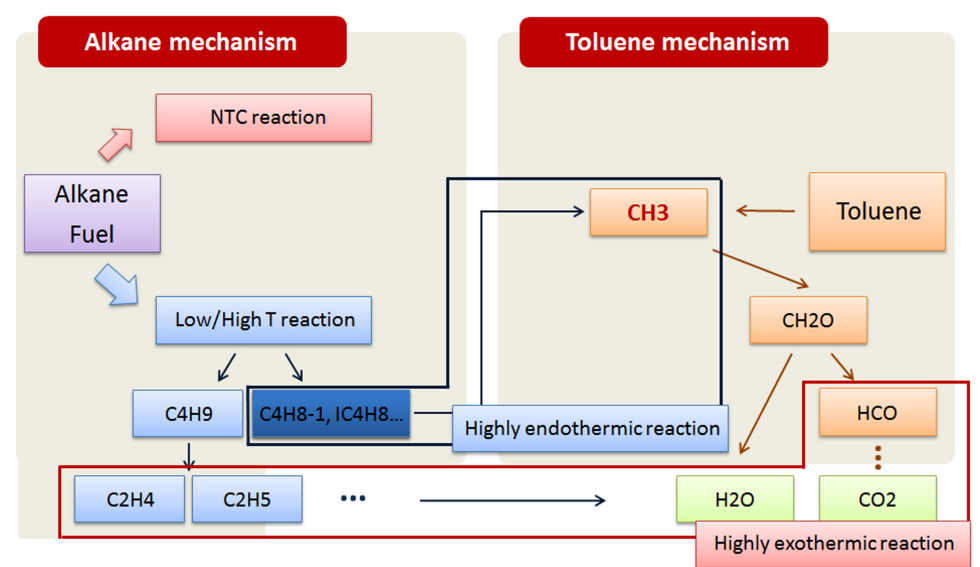

Fig. 8 Reaction diagram of mixtures with paraffins and toluene

역 일부에서 상대적으로 반응성이 낮은 톨루엔을 섞었을 때 오히려 점화 지연 시간이 짧아지는 결과 를 보였다. 이런 경향은 M. Hartmann 등의 실험에서 도 발견된 경향이다. ${ }^{8)}$

이러한 현상의 원인은 Fig. 8에서도 알 수 있듯이, 단일 성분의 해석 결과에서 톨루엔의 반응성이 가 장 낮았지만 톨루엔의 반응으로부터 생성되는 메틸 기 $\left(\mathrm{CH}_{3}\right)$ 가 파라핀 족의 반응 중 흡열반응을 억제시 키고, 오히려 발열반응을 촉진시키면서 오히려 반 응속도가 빨라진 결과로 판단된다.

더 자세한 분석을 위해 반응 계수 분석을 사용하 였다. Fig. 9는 $100 \%$ 노멀 도데케인의 반응 경로와 노멀 도데케인 $90 \%$, 톨루엔 $10 \%$ 혼합물의 반응 경 로를 반응이 $0.3 \mathrm{~ms}$ 진행된 시점에서 나타낸 것이다. 톨루엔을 포함한 혼합물의 경우가 Fig. 8 의 흡열반 응에 해당하는 반응계수는 줄고 발열반응에 해당하 는 반응계수는 늘어나는 것을 확인할 수 있다. 또한 이 시점의 온도도 증가한 것으로 보아, 톨루엔을 일 정량 혼합하였을 때 반응이 오히려 활발하게 진행 되는 것을 확인할 수 있다.

이런 현상은 파라핀 족의 흡열반응과 발열반응이 주로 초기온도가 고온이거나 저온일 때 주로 진행되 기 때문에 해당 영역에서 두드러지게 나타나게 된다.

톨루엔이 일정 비율 이상 포함된 혼합물에서는 톨루엔의 낮은 반응성의 영향이 더욱 지배적이므 로, Case 4 와 5 의 경우에는 이러한 현상이 나타나지 않는다. 하지만 상용 디젤유는 방향족을 $30 \sim 40 \%$ 이

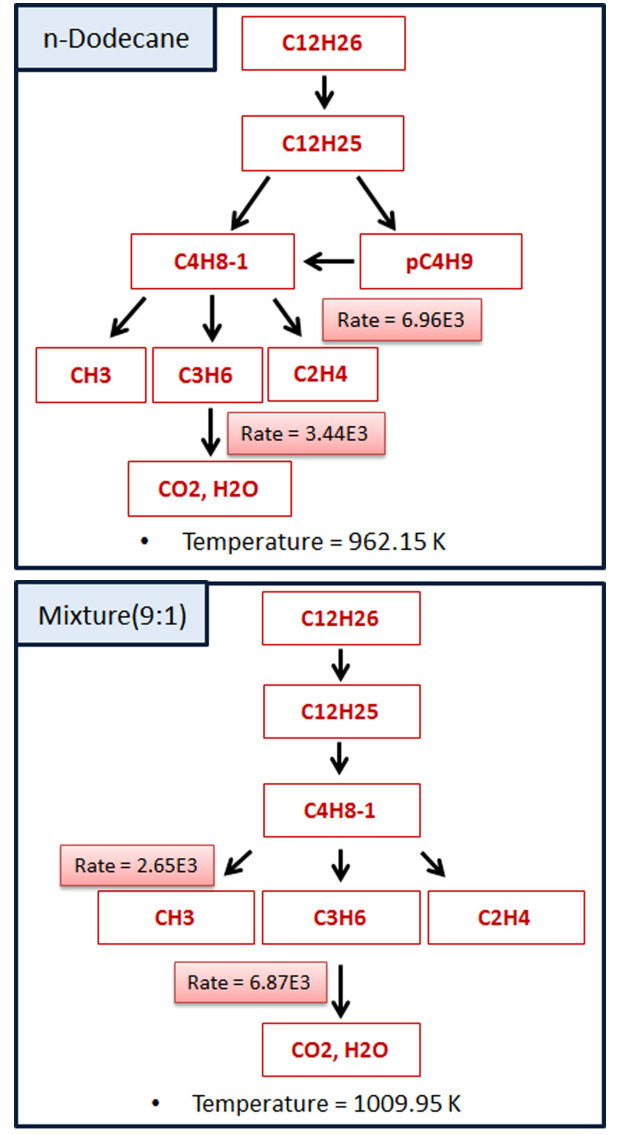

Fig. 9 Reaction path diagrams of n-dodecane and its mixture included $10 \%$ toluene

상 포함하고 있지 않기 때문에, ${ }^{14)}$ 이 이상의 톨루엔 혼합물에 대한 추가 연구는 진행되지 않았다. 


\subsection{3성분 혼합물}

앞선 2성분 혼합물의 점화 지연 시간 및 각 화학 종의 영향이 유의미한 결과가 되기 위해서는, 위의 결과들이 세 성분을 모두 포함한 혼합물의 결과에 서도 그 경향성을 보여야만 한다. 따라서 나머지 화 학종의 상대적 비율은 유지한 채 톨루엔의 상대적 비율을 변화시켜 가면서 수행한 표본 1 4와 ${ }^{8-10)}$, 톨 루엔의 비율은 고정한 채로 노멀 도데케인과 이소 옥탄의 상대적 비율을 변화시켜 가면서 계산을 수 행한 표본 5 $8^{8-10)}$ 로 나누어 결과를 도출하였다. 상 세한 혼합 비율은 Table 4와 같다.

Table 4 Case conditions for paraffin \& toluene mixture (composition was calculated as mole(volume) percent)

\begin{tabular}{|c|c|c|c|}
\hline Case number & n-dodecane $(\%)$ & iso-octane $(\%)$ & toluene(\%) \\
\hline 1 & 45 & 45 & 10 \\
\hline 2 & 40 & 40 & 20 \\
\hline 3 & 35 & 35 & 30 \\
\hline 4 & 30 & 30 & 40 \\
\hline 5 & 50 & 20 & 30 \\
\hline 6 & 40 & 30 & 30 \\
\hline 7 & 30 & 40 & 30 \\
\hline 8 & 20 & 50 & 30 \\
\hline
\end{tabular}

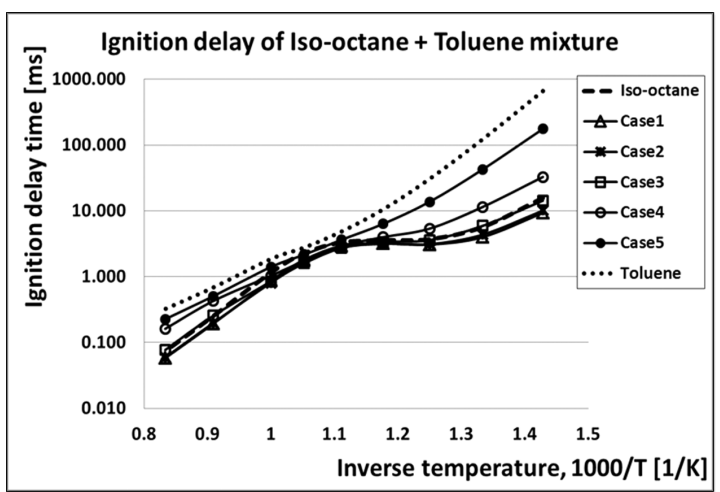

Fig. 10 Ignition delay time of mixtures of $n$-dodecane, isooctane and toluene with constant paraffin compositions at $\mathrm{p}=40$ bar, elevated temperature under stoichiometric condition

Fig. 10은 노멀 도데케인과 이소 옥탄의 비율을 1:1로 고정한 채 톨루엔의 비율을 바꿔가며 계산한 점화 지연 결과이다. 톨루엔이 첨가된 후 저온과 고 온 영역에서 점화 지연 시간이 짧아진 것을 확인할

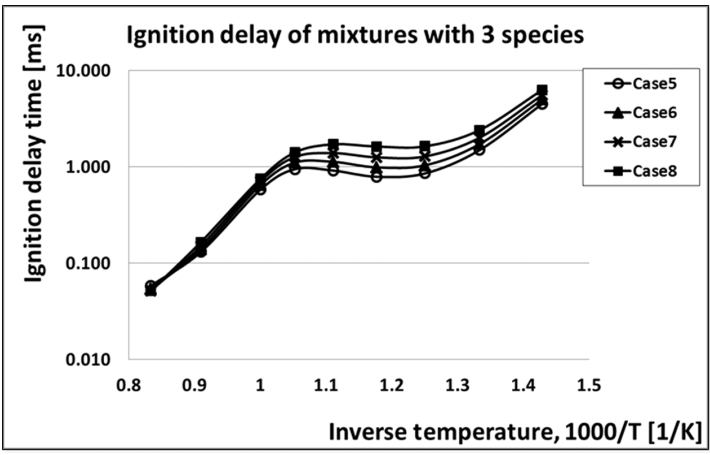

Fig. 11 Ignition delay time of mixtures of n-dodecane, isooctane and toluene with constant toluene compositions at $\mathrm{p}=40$ bar, elevated temperature under stoichiometric condition

수 있으며, 이는 앞선 파라핀 족과 톨루엔 혼합물의 점화 지연 시간의 경향과 일치함을 확인할 수 있다.

Fig. 11은 Case5 8, 즉 톨루엔의 비율을 $30 \%$ 로 고 정한 채 노멀 도데케인과 이소 옥탄의 상대적 비율 을 바꿔 가며 계산한 점화 지연 결과이다. 이소 옥탄 의 비율이 증가할수록 모든 온도 영역에서 점화 지 연 시간이 길어짐을 확인할 수 있고, 이 역시 앞서 밝혔던 노멀 도데케인과 이소 옥탄 혼합물의 점화 지연 시간의 경향과 일치함을 확인할 수 있다.

결과적으로 세 성분을 모두 포함한 혼합물 역시 2 성분 혼합물에서 분석하였던 점화 지연 시간의 경 향과 잘 일치함을 알 수 있다.

\section{4. 결 론}

1) 노멀 도데케인, 이소 옥탄, 톨루엔을 각각 대표 화학종으로 포함한 모사 디젤 화학반응 모델을 이용하여 각 성분의 포함 비율에 따른 혼합물의 화학적인 점화 지연 시간의 영향을 알아보았다.

2) 노멀 도데케인과 이소 옥탄은 파라핀 계열의 연 료로써 NTC 영역이 나타났으며, 톨루엔은 NTC 영역이 나타나지 않고 상대적으로 긴 점화 지연 시간을 가지는 것으로 나타났다. 이는 톨루엔의 낮은 반응성과 단일 반응 경로에 기인한다.

3 ) 노멀 도데케인과 이소 옥탄을 포함한 혼합물은 이소 옥탄의 비율이 증가할수록 점화 지연 시간 이 길어지는 경향을 보였는데, 이는 두 화학종이 같은 파라핀 계열로 비슷한 반응 메커니즘을 따 
르기 때문으로 보인다.

4) 위의 두 파라핀 계열과 톨루엔을 포함한 혼합물 의 경우 일정량 이하의 톨루엔이 포함된 표본에 대해 초기온도가 고온인 영역과 저온인 영역에 서 오히려 점화 지연 시간이 짧아졌다. 이는 톨루 엔의 연소반응으로부터 생성되는 메틸기 $\left(\mathrm{CH}_{3}\right)$ 의 영향으로 보인다.

5) 1) 4)의 결과는 향후 모사 디젤 모델과 실험 결과 의 비교 시 각 화학종의 상대적 비율을 결정할 수 있는 기준으로 사용할 수 있을 것으로 판단된다.

\section{후 기}

본 연구는 현대자동차의 후원과 2차 Brain Korea, 서울대학교 정밀기계설계공동연구소(SNU-IAMD) 의 지원으로 수행되었으며 이에 감사드립니다.

\section{References}

1) W. J. Pitz and C. J. Mueller, "Recent Progress in the Development of Diesel Surrogate Fuels," Progress in Energy and Combustion Science, Vol.37, Issue 3, pp.330-350, 2011.

2) U. B. Azimov and K. S. Kim, "Large-eddy Simulation of Air Entrainment during Diesel Spray Combustion with Multi-dimensional CFD," Int. J. Automotive Technology, Vol.12, No.6, pp.795-812, 2011.

3) U. B. Azimov, K. S. Kim, D. S. Jeong and Y. G. Lee, "Evaluation of Low-temperature Diesel Combustion Regimes with n-Heptane Fuel in a Constant-volume Chamber," Int. J. Automotive Technology, Vol.10, No.3, pp.265-276, 2009.

4) S. Lee, K. Min and J. Chung, "The Effects of Injection Timing and Piston Bowl Shape on PHCCI Combustion with Split Injections," SAE 2010-01-0359, 2010.

5) V. P. Zhukov, V. A. Sechenov and A. Yu. Starikovskii, "Autoignition of n-Decane at High Pressure," Combustion and Flame, Vol.153, Issues 1-2, pp.130-136, 2008.
6) K. Narayanaswamy, G. Blanquart and H. Pitsch, "A Consistent Chemical Mechanism for Oxidation of Substituted Aromatic Species," Combustion and Flame, Vol.157, Issue 10, pp.18791898, 2010.

7) M. Hartmann, I. Gushterova, M. Fikri, C. Schulz, R. Schie $\beta 1$ and U. Maas, "Auto-ignition of Toluene Doped n-Heptane and Iso-octane/air Mixtures: High-pressure Shock-tube Experiments and Kinetic Modeling," Combustion and Flame, Vol.158, Issue 1, pp.172-178, 2011.

8) Y. Kim, A Study on the CAI Combustion Characteristics Using a Reduced Chemical Kinetic Mechanism, Ph. D. Dissertation, Seoul National University, Seoul, 2007.

9) K. Lee, Y. Kim and K. Min, "Development of a Reduced Chemical Kinetic Mechanism for a Gasoline Surrogate for Gasoline HCCI Combustion," Combustion Theory and Modelling, Vol.15, No.1, pp.107-124, 2011.

10) S. Lee, G. Kim and K. Min, "Development of Reduced Normal Dodecane Chemical Kinetics," SAE 120120017, 2012.

11) J. B. Heywood, Internal Combustion Engine Fundamentals, McGraw-Hill, New York, pp.539540, 1988.

12) S. National Laboratories, CHEMKIN-IV: A Fortran Chemical Kinetics Package for the Analysis of Gas-phase Chemical and Plasma Kinetics, 1994.

13) S. S. Vasu, D. F. Davidson, Z. Hong, V. Vasudevan and R. K. Hanson, "n-Dodecane Oxidation at High Pressures: Measurements of Ignition Delay Times and $\mathrm{OH}$ Concentration Time Histories," Proc. Combust. Inst, Vol.32, pp.173-180, 2009.

14) Y. Briker, Z. Ring, A. Iacchelli, N. Mclean, P. M. Rahimi and C. Fairbrige, "Diesel Fuel Analysis by GC-FIMS: Aromatics, n-Paraffins and Isoparaffins," Energy and Fuels, Vol.15, pp.23-37, 2001. 